\title{
Evaluation of Calphad Approach and Empirical Rules on the Phase Stability of Multi-principal Element Alloys
}

\author{
Song-Mao Liang ${ }^{1}$ (D) Rainer Schmid-Fetzer $^{1}$
}

Submitted: 14 April 2017/in revised form: 19 June 2017/Published online: 10 July 2017

(C) ASM International 2017

\begin{abstract}
The formation of single disordered solid solution phase in multi-principal element alloys (MPEAs) is crucial for the properties of the alloy, and thus several empirical rules have been proposed to predict the stability of disordered solid solution phase in MPEAs. Compared to these empirical rules, Calphad approach provides a more reliable and quantitative prediction. In the present work, we choose three model systems of $\mathrm{Al}_{x} \mathrm{CoCrFeNi}, \mathrm{CoCr}_{x} \mathrm{FeMnNi}$ and $\mathrm{Al}_{x} \mathrm{LiMgSnZn}$ to evaluate these empirical rules by comparing with the Calphad calculated results. The Calphad calculated temperature-composition sections reveal the effect of composition on the phase formation under equilibrium condition. Corresponding diagrams along these sections illustrate parameter variations from empirical rules associated with alloy compositions and highlight predictions and limitations. The impact of the different sources of atomic size data is also discussed.
\end{abstract}

Keywords Calphad · empirical rules · high entropy alloys · multi-principal element alloys (MPEAs) · phase stability

\section{Introduction}

The concept of High Entropy Alloys (HEAs) was initially proposed based on equiatomic multi-component alloys consisting of a single disordered solid solution (DSS) phase. ${ }^{[1,2]}$ The HEAs attract attention due to their promising properties such as excellent strength, hardness and wear resistance,

Song-Mao Liang

songmao.liang@gmail.com; songmao.liang@tu-clausthal.de

1 Institute of Metallurgy, Clausthal University of Technology, Robert-Koch-Str. 42, 38678 Clausthal-Zellerfeld, Germany exceptional mechanical performance both at high and cryogenic temperatures, as well as high corrosion resistance ${ }^{[3]}$ Later research showed that also non-equiatomic multi-component alloys with dual-phase structure, ${ }^{[4]}$ or with a solid solution phase strengthened by hard intermetallic compounds, ${ }^{[5]}$ exhibit excellent combinations of strength and ductility. Then the term compositionally complex alloys ${ }^{[6]}$ or complex concentrated alloys (CCAs) ${ }^{[7]}$ describes the characteristics of these alloys more appropriately. The concentrations of all elements in these alloys are similar, and each element can be as "principal" for the alloys. Thus, the term multi-principal element alloys (MPEAs) was designated in contrast to traditional iron, titanium, magnesium, aluminum alloys, which generally contain only one or two principal elements. In the literature, the terms HEAs, CCAs and MPEAs are not distinguished and often used interchangeably for these alloys. To give a clear usage of these terms in this article, we specify the MPEAs as a general term for these series of alloys, the HEAs as single disordered solution phase alloys and the CCAs as dual-phase or multiphase alloys.

One of the hot topics of the ongoing research on MPEAs is to to find a proper method to predict an alloy containing only one single DSS phase, i.e., HEAs, as opposed to multiple phases, i.e., CCAs. In order to achieve this, several empirical rules ${ }^{[8-21]}$ have been proposed trying to predict the interface or boundary between the HEAs and CCAs, which we define here as the HEA/CCA interface.

Compared to empirical rules, the Calphad approach provides a more reliable and quantitative prediction on the HEA/ CCA interface when a validated thermodynamic description of the system is available. ${ }^{[22-28]}$ In the present work, we will explore the HEA/CCA interface of three typical quinary $\mathrm{AlCoCrFeNi}, \mathrm{CoCrFeMnNi}$ and AlLiMgSnZn systems through the Calphad approach, and then evaluate all parameters obtained from empirical rules by comparison of the Calphad calculations to the empirical predictions. 


\section{Summary of Empirical Rules Proposed in the Literature}

The proposed empirical rules in the literature to predict the phase stability of the multicomponent DSS phase in MPEAs are essentially divided into two groups. The first group is based on Hume-Rothery rules, ${ }^{[14,29]}$ such as atomic size difference parameters, electronegativity $\chi$, electron concentration ( $(e / a)$ and valence electron concentration (VEC). The second group is using parameters which are essentially derived from thermodynamic property values, such as $\Delta H, \Delta S$ and $\Delta G$ and temperature, but notice the meaning of $\Delta$ differ greatly in different empirical rules, which will be explained in detail later.

\subsection{Parameters Based on Hume-Rothery Rules}

\subsubsection{Atomic Size Difference}

The atomic size effect is the most convincing rule in Hume-Rothery rule. For a binary system, solid solution phase can only be formed when the atomic size difference between solute and solvent element is less than $15 \% .^{[30]}$ The most widely used parameter to evaluate the atomic size difference in multicomponent alloys is the $\delta_{\mathrm{r}}$ parameter, which is defined as:

$\delta_{\mathrm{r}}=\sqrt{\sum_{i=1}^{N} c_{i}\left(1-r_{i} / \bar{r}\right)^{2}} \cdot 100 \% ; \quad \bar{r}=\sum_{i=1}^{N} c_{i} r_{i}$

where $N$ is the number of components; $c_{i}$ is the atomic fraction of the $i$ th component; $r_{i}$ is the atomic radius of the $i$ th component. The parameter of $\delta_{\mathrm{r}}$ was firstly introduced by Zhang et al. ${ }^{[8]}$ to predict the formation of DSS phase in MPEAs, and then accepted by other researchers. ${ }^{[7,9-11]}$ The value of $\delta_{\mathrm{r}}=6.6 \%$ was considered as a critical value for the formation of DSS phase. The condition of $\delta_{\mathrm{r}} \leq 6.6 \%$ is the necessary condition for the formation of DSS phase. ${ }^{[10,13,14]}$

Wang et al. ${ }^{[15]}$ claimed that the $\delta_{\mathrm{r}}$ parameter did not describe the solubility of HEAs very well, and they proposed another parameter $\gamma$, which is defined as:

$\gamma=\left(1-\sqrt{\frac{\left(r_{\mathrm{S}}+\bar{r}\right)^{2}-\bar{r}^{2}}{\left(r_{\mathrm{S}}+\bar{r}\right)^{2}}}\right) /\left(1-\sqrt{\frac{\left(r_{\mathrm{L}}+\bar{r}\right)^{2}-\bar{r}^{2}}{\left(r_{\mathrm{L}}+\bar{r}\right)^{2}}}\right)$

(Eq 2)

where $r_{\mathrm{L}}$ and $r_{\mathrm{S}}$ are the radii of the largest and smallest atoms in the alloy. Besides the average of the atomic radii, the largest and smallest atoms in multicomponent alloy systems also play a role in stability of the DSS phase. They concluded that $\gamma<1.175$ was the necessary condition for determining the solubility of the multicomponent alloys. Their collected multicomponent alloys with multiphase regions and metallic glasses are all distributed in the region of $\gamma>1.175 .^{[15]}$

\subsubsection{Pauling Electronegativity}

The electronegativity difference $\Delta \chi$ is defined as

$\Delta \chi=\sqrt{\sum_{i=1}^{N} c_{i}\left(\chi_{i}-\bar{\chi}\right)^{2}}$

where $\bar{\chi}=\sum^{N} c_{i} \chi_{i}$ and $\chi_{i}$ is the electronegativity of element $i$.

Rather thān using a single critical value, Yang et al. ${ }^{[16]}$ proposed to use $\Delta \chi$ value range to predict the formation of solid solution phases. Their analyzed results showed that HEAs typically have values of $\Delta \chi$ around $0.1-0.15$, and CCAs are around 0.15-0.25, for low density CCAs are 0.15-0.40.

\subsubsection{Electron Concentration}

According to Hume-Rothery rule, the electron concentration plays a key role in stabilizing some particular phases in alloys. ${ }^{[29,30]}$ The electron concentration is basically described by two definitions: number of electron per atom, ela, or the valence electron concentration (VEC). For a multicomponent alloy, the $e / a$ and VEC are often defined by the weighted average value from the constituent components.

$e / a=\sum_{i=1}^{N} c_{i}(e / a)_{i}$

or

$\mathrm{VEC}=\sum_{i=1}^{N} c_{i}(\mathrm{VEC})_{i}$,

where $(e / a)_{i}$ and $(\mathrm{VEC})_{i}$ are the $e / a$ and VEC for the individual element. The determination of the $e / a$ value for transition metal (TM) elements is difficult and controversial. ${ }^{[31]}$ The ela value of some TM elements even varies in different environment. Guo et al. ${ }^{[9]}$ proposed to use VEC to study the electron concentration effect on the phase stability of HEAs. They concluded that except the Mn-containing HEA alloys, other HEA alloy systems, such as $\mathrm{AlCoCrCuFeNi}$ and MoNbTaVW, satisfy the condition that the alloys with VEC $\geq 8.0$ contain one single Fcc phase, VEC $<6.87$ for one single Bcc phase alloys, and $6.87 \leq \mathrm{VEC}<8.0$ for fcc + Bcc two-phase alloys. The VEC rule is also discussed in detail in Ref 32 .

\subsection{Parameters Associated with Thermodynamic Properties}

\subsubsection{Entropy of Mixing}

The concept of high entropy alloy (HEA) was initially proposed due to the high configurational entropy of mixing 
of the alloys $\left(\Delta S_{\mathrm{c}}\right)$ with equiatomic 5 or more elements. It was proposed that the formation of the intermetallic phases could be suppressed due to the high entropy effect of the alloys. ${ }^{[2]}$ Although some later research as summarized in Ref 7 indicates that high entropy effect alone is not the determining factor for the suppression of the intermetallic phases, the high entropy alloy is becoming the most popular term for this type of the alloys, and the configurational entropy of mixing $\left(\Delta S_{\mathrm{c}}\right)$ is often used as a replacement of entropy of mixing $\left(\Delta S_{\text {mix }}\right)$ of the alloys to evaluate the DSS phase stability of the HEAs.

Besides the configurational contribution, some other effects also contribute significantly to the entropy of mixing and cannot be ignored in many cases. Ye et al. ${ }^{[18]}$ proposed a method by applying the hard sphere model ${ }^{[33]}$ to calculate the excess entropy of the mixing, $\Delta S_{\mathrm{E}}$. The $\Delta S_{\mathrm{E}}$ is generally expressed as $\Delta S_{\mathrm{E}}=\Delta S_{\mathrm{E}}\left(c_{i}, r_{i}, \xi\right)$, where $c_{i}$ and $r_{i}$ are the mole fraction and atomic radius of the $i$ th element, and $\xi$ is the atomic packing fraction of the $n$-element alloy ranging from 0.68 to 0.74 for close atom packing at room temperature. The full set of equations used to calculate $\Delta S_{\mathrm{E}}$ are very tedious and not repeated here for brevity. Interested readers are recommended to refer to the original references. ${ }^{[18,33]}$ Note that here $\Delta S_{\mathrm{E}}$ is a thermodynamic property, but it is the atomic radius that plays a key role.

\subsubsection{Enthalpy of Mixing}

Enthalpy of mixing $\left(\Delta H_{\text {mix }}\right)$ is also regarded as an indicator for the formation of single disordered solution phase. The $\Delta H_{\text {mix }}$ is determined approximately as:

$\Delta H_{\mathrm{mix}}=\sum_{i=1, i \neq j}^{N} \omega_{i j} c_{i} c_{j}$

where $\omega_{i j}=4 \Delta H_{A, B}^{\operatorname{mix}}$ is the regular-interaction parameter between $i$ th and $j$ th elements. Essentially, the $\Delta H_{\text {mix }}$ should be the enthalpy of the mixing of the single DSS phase of the HEAs, but we accept the enthalpy of mixing of the liquid phase calculated by the Miedema's macroscopic model $^{[34-36]}$ for the $\Delta H_{A, B}^{\text {mix }}$ as the same method used in the references. ${ }^{[8-10,12]}$ It was proposed that when the $\Delta H_{\text {mix }}$ value is close to zero, then the tendency of forming single DSS phase is large. Different researchers proposed different critical values for $\Delta H_{\text {mix }}$ region of forming one single phase. It was suggested a range of $-15 \mathrm{~kJ} \mathrm{~mol}^{-1}$ $\leq \Delta H_{\text {mix }} \leq 5 \mathrm{~kJ} \mathrm{~mol}^{-1}$ in Ref 10 ; while a range of $-11.6 \mathrm{~kJ} \mathrm{~mol}^{-1}<\Delta H_{\text {mix }}<3.2 \mathrm{~kJ} \mathrm{~mol}^{-1}$ in Ref 12 .

\subsubsection{The $\Omega$ Parameter ${ }^{[10]}$}

Considering that neither the entropy of mixing nor enthalpy of mixing alone is so effective on predicting the phase stability of the solid solution phase, Yang and Zhang ${ }^{[10]}$ proposed a combined parameter of $\Omega$, which is defined as

$\Omega=\frac{T_{\mathrm{m}} \Delta S_{\mathrm{mix}}}{\left|\Delta H_{\mathrm{mix}}\right|}$,

in which $\Delta \mathrm{S}_{\mathrm{mix}}$ is the entropy of mixing which is often replaced by the configurational entropy of mixing $\Delta \mathrm{S}_{\mathrm{c}} . \Delta H_{\text {mix }}$ is the enthalpy of mixing of the solid solution phase, also often replaced by the enthalpy of the mixing of the liquid phase, and estimated based on the Miedema's model as detailed in section 2.2.2. $T_{\mathrm{m}}$ is described as the melting temperature of $n$ element alloy and calculated by the rule of mixtures:

$T_{\mathrm{m}}=\sum_{i=1}^{N} c_{i}\left(T_{\mathrm{m}}\right)_{i}$.

By compared with the collected experimental data, a critical condition for the formation of the single solid solution phase with $\Omega>1.1$ was proposed in Ref 10 .

\subsubsection{The $\phi$ Parameter ${ }^{[19]}$}

After derived the value of $\Delta S_{\mathrm{E}}$ based on hard sphere model, ${ }^{[18]}$ Ye et al. ${ }^{[19]}$ proposed a new $\phi$ parameter defined as

$\phi=\frac{\Delta S_{\mathrm{C}}-\Delta S_{\mathrm{H}}}{\left|\Delta S_{\mathrm{E}}\right|}$

where $\Delta S_{\mathrm{C}}$ is the configurational entropy of mixing, $\Delta S_{\mathrm{E}}$ is the excess entropy of mixing that is a function of atomic packing and atom size, calculated from Ref $18, \Delta S_{\mathrm{H}}$ is defined as $\Delta S_{\mathrm{H}}=\mathrm{I} \Delta H_{\mathrm{mix}} \mathrm{I} / T_{\mathrm{m}}$, with $\Delta H_{\text {mix }}$ is calculated based on the Miedema's model as described in section 2.2.2. $T_{\mathrm{m}}$ is the average melting point $T_{\mathrm{m}}$ of the elements as treated in section 2.2.3. They proposed a critical value of $\phi_{\mathrm{c}} \sim 20$. The MPEA alloy tends to display a single-phase solid solution when $\phi>\phi_{\mathrm{c}}$, and multi-phase structure when $\phi<\phi_{\mathrm{c}}$.

\subsubsection{The $\Phi$ Parameter ${ }^{[20]}$}

By considering the competition effect of the Gibbs energy of the intermetallic phases and the DSS phases, King et al. ${ }^{[20]}$ proposed a $\Phi$ parameter, which is defined as

$\Phi=\frac{\Delta G_{\mathrm{SS}}}{-\left|\Delta G_{\max }\right|}$

where $\Delta G_{\mathrm{SS}}=\Delta H_{\mathrm{ss}}-T \Delta S_{\mathrm{ss}}$ is the formation Gibbs energy of the DSS phase with references to its individual elements. The $\Delta H_{\mathrm{ss}}$ is calculated by the Miedema's model for solid solution phase ${ }^{[34]}$ as detailed in the supplementary file of Ref 20 which is different from the Miedema's model for liquid phase applied for $\Delta H_{\text {mix }}$ calculations as described in 
section 2.2.2; the $\Delta S_{\mathrm{ss}}$ also only considers the configurational entropy of mixing as described in section 2.2.1. The $\Delta G_{\max }$, which could be the lowest value (negative) for intermetallic phases or the highest value (positive) for segregation, is the absolute maximum value of Gibbs energy of formation obtained from the possible binary sub-systems of the MPEA alloy system. For the intermetallics (IM) they treated the $\Delta S_{\text {int }}=0$; and, thus, obtained $\Delta G_{\text {int }}=\Delta H_{\text {int }}$. The detailed description of this rule is given in the original paper. ${ }^{[20]}$ The values of all these parameters can be calculated using their website: www.alloyASAP.com.

They proposed that the alloys with $\Phi>1$ are HEAs containing only one single solid solution phase, while the alloys with negative value of $\Phi$ are CCAs containing more than one phases.

\subsubsection{The $\kappa$ Parameter ${ }^{[1]]}$}

Senkov and Miracle ${ }^{[11]}$ proposed a linear relationship for the enthalpies and entropies between solid solution phases and intermetallic phases i.e.,

$\kappa_{1}=\Delta H_{\mathrm{IM}} / \Delta H_{\mathrm{SS}}$ and $\kappa_{2}=\Delta S_{\mathrm{IM}} / \Delta S_{\mathrm{SS}} ;$

For an alloy system, the thermodynamic condition for the formation of a solid solution phase at temperature $T$ is $\Delta G_{\mathrm{ss}}<\Delta G_{\mathrm{IM}}$, i.e.,

$\Delta H_{\mathrm{ss}}-T \Delta S_{\mathrm{sS}}<\Delta H_{\mathrm{IM}}-T \Delta S_{\mathrm{IM}}$.

Combining Eq 11 and 12 results in:

$$
\begin{aligned}
\kappa_{1} & =\Delta H_{\mathrm{IM}} / \Delta H_{\mathrm{SS}}<-\left(1-\kappa_{2}\right) T \Delta S_{\mathrm{SS}} / \Delta H_{\mathrm{SS}}+1 \\
& =\kappa_{1}^{\mathrm{cr}}(\mathrm{T}) .
\end{aligned}
$$

where

$\Delta H_{\mathrm{IM}}=\sum_{i=1, i \neq j}^{N} 4 H_{i j}^{\mathrm{IM}} c_{i} c_{j}$

$H_{i j}^{\mathrm{IM}}$ is the formation of enthalpy of the compound with the most negative value in the binary subsystems. The $H_{i j}^{\mathrm{IM}}$ values can be obtained from the density-functional-theory (DFT) calculated results such as the appendix table in Ref 17 or online databases, ${ }^{[37,38]}$ which are also cited in Ref 17 or open quantum materials database (OQMD) ${ }^{[39-41]}$ and Materials Project database (www.materialsproject.org) ${ }^{[42]}$ to name just a few in this incomplete list. However, one should keep in mind that the $H_{i j}^{\mathrm{IM}}$ values from different sources may also differ greatly. Take Al-Mg system for example, $H_{i j}^{\mathrm{IM}}$ is the enthalpy formation of $\mathrm{Mg}_{17} \mathrm{Al}_{12}$ phase which has the most negative value. This value is $0.033 \mathrm{eV}$ atom $^{-1}$ provided in Ref 17 but it is $0.024 \mathrm{eV}$ atom $^{-1}$ in OQMD ${ }^{[39]} 0.02 \mathrm{eV}$ atom ${ }^{-1}$ in Materials Project, ${ }^{[42]} 0.0384 \mathrm{eV}^{-1}$ atom $^{-1}$ in Ref 37 and two values of 0.0375 and $0.0366 \mathrm{eV}$ atom $^{-1}$ in http://aflowlib. org. ${ }^{[38]}$ In the present work, the data from Ref 17 which are accepted in Ref 11 are used for $\mathrm{AlCoCrFeNi}$ and $\mathrm{CoCr}$ FeMnNi systems calculation. But the $H_{i j}^{I M}$ values for Al-Li, $\mathrm{Li}-\mathrm{Mg}, \mathrm{Li}-\mathrm{Zn}, \mathrm{Mg}-\mathrm{Sn}$ and $\mathrm{Sn}-\mathrm{Zn}$ binary systems, which are not available in Ref 17 are taken from OQMD. ${ }^{\text {[39] }}$

The enthalpy of formation of the solid solution phase $\left(\Delta H_{\mathrm{SS}}\right)$ is simplified as the enthalpy of mixing $\Delta H_{\text {mix }}$, as described in section 2.2.2. The entropy of formation of the solid solution phase $\left(\Delta S_{\mathrm{SS}}\right)$ is also simplified as the configurational entropy of mixing $\left(\Delta S_{\mathrm{c}}\right)$. The $\kappa_{2}$, a structural ordering related parameter, can be estimated by the site occupancy in the sublattice model of IM phases. ${ }^{[7]}$ The value of $\kappa_{2}$ could increases from 0.4 to 0.8 with decreasing the level of ordering of the IM phase, and a middle value of $\kappa_{2}=0.6$ was applied in Ref 11 for their prediction.

Thus, the condition of suppression IM phases at temperature $T$ is simplified as,

$\kappa_{1}<\kappa_{1}^{\mathrm{cr}}(T), \quad$ i.e., $\Delta H_{\mathrm{IM}} / \Delta H_{\mathrm{SS}}<\kappa_{1}^{\mathrm{cr}}(T)$

This inequality condition looks simple, but it is actually equivalent to the condition of $\Delta G_{\mathrm{ss}}<\Delta G_{\mathrm{IM}}$. All the properties values for $\Delta G_{\mathrm{ss}}$ and $\Delta G_{\mathrm{IM}}$ are required from empirical rules estimations and DFT calculations.

\subsection{Parameters Combining Atomic Size and Thermodynamic Properties}

\subsubsection{The 1 Parameter ${ }^{[21]}$}

Singh et al. ${ }^{[21]}$ proposed one parameter $\Lambda$ by combining the thermodynamic property of $\Delta S_{\text {mix }}$ and the atomic size difference parameter $\delta_{\mathrm{r}}$, defined as

$\Lambda=\Delta S_{\text {mix }} / \delta_{\mathrm{r}}^{2}$

in which the $\Delta \mathrm{S}_{\text {mix }}$ is also simplified by using $\Delta S_{\mathrm{c}}, \delta_{\mathrm{r}}$ is the same atomic size difference parameter as described in section 2.1.1. They recommended that single DSS phase tends to be formed in alloys with $\Lambda>0.95$; solid solution phases together with compounds tend to be formed in alloys with $\Lambda$ value between 0.95 and 0.24 ; intermetallic compounds are formed in alloys with $\Lambda<0.24$.

\section{Calculations Based on Calphad Approach and Empirical Rules}

The Pandat ${ }^{\mathrm{TM}}$ software ${ }^{[43]}$ has been used for Calphad calculations. The PanHEA database, www.computherm. com, was used for $\mathrm{AlCoCrFeNi}$ and $\mathrm{CoCrFeMnNi}$ system calculations, while a magnesium database development by our group $(\mathrm{MgDB})^{[44]}$ was used for AlLiMgSnZn system. The PanHEA database contains the full thermodynamic 
Table 1 Data for the elements used in the present work

\begin{tabular}{llllc}
\hline Elements & $r_{\mathrm{i}}, \mathrm{pm}(\mathrm{a})$ & $T_{\mathrm{m}}, \mathrm{K}(\mathrm{b})$ & $\chi(\mathrm{c})$ & $\mathrm{VEC}(\mathrm{d})$ \\
\hline $\mathrm{Al}$ & 143 & 933.473 & 1.61 & 3 \\
$\mathrm{Co}$ & 125 & 1768 & 1.88 & 9 \\
$\mathrm{Cr}$ & 128 & 2180 & 1.66 & 6 \\
$\mathrm{Fe}$ & 127 & 1810.94 & 1.83 & 8 \\
$\mathrm{Li}$ & 156 & 453.6 & 0.98 & 1 \\
$\mathrm{Mg}$ & 160 & 923 & 1.31 & 2 \\
$\mathrm{Mn}$ & 126 & 1519 & 1.55 & 7 \\
$\mathrm{Ni}$ & 125 & 1728.3 & 1.91 & 10 \\
$\mathrm{Sn}$ & 155 & 505.08 & 1.96 & 4 \\
$\mathrm{Zn}$ & 139 & 692.68 & 1.65 & 12 \\
\hline
\end{tabular}

(a)Values taken from the metallic atomic radius data in Ref 47

(b)Values taken from Ref 48

(c) Values taken from Ref 49

(d)Values taken from Ref 9 identical to Ref 46

descriptions on all the binary and ternary sub-systems of $\mathrm{AlCoCrFeNi}$ and $\mathrm{CoCrFeMnNi}$ systems, and the reliability of these systems has also been validated and discussed in Ref 22-25. The calculated results using Thermo-calc ${ }^{[45]}$ with TCNI7 database also show good agreement with experimental data for $\mathrm{AlCoCrFeNi}$ and $\mathrm{CoCrFeMnNi}$ systems, ${ }^{[25,26]}$ but the encrypted TCNI7 database is not yet available in the authors' group, thus the differences between TCNI7 and PanHEA are not compared in detail. In MgDB database, ${ }^{[44]}$ all the binary sub-systems and the ternary sub-systems of Al-Li-Mg, Al-Mg-Sn, Al-Mg-Zn, Al-Sn-Zn, Li-Mg-Zn, and Mg-Sn-Zn in AlLiMgSnZn system have the full thermodynamic descriptions. Therefore, in this work we did not compare the Calphad results with the experimental work in detail, which are normally required, but used the Calphad calculated results for evaluation and discussion the reliability of the empirical rules.

The values of the parameters from empirical rules are also calculated in this work with the equations described in section 2. Data for the elements are listed in Table 1. ${ }^{[9,46-49]}$ The $\Delta H_{A, B}^{\text {mix }}$ values used for $\Delta H_{\text {mix }}$ calculations are obtained from Ref 36 and $\Delta H_{\mathrm{IM}}$ data from Ref 17 and OQMD ${ }^{[39]}$ are shown in Table 2 . The $\Phi$ parameter ${ }^{[20]}$ values are directly calculated using the website, developed by King and McGregor: www.alloyASAP.com. ${ }^{[50]}$

\section{Calphad Calculation Results and Evaluation of the Empirical Rules}

\subsection{Al-Co-Cr-Fe-Ni System}

Figure 1(a) shows the Calphad calculated temperature-concentration section of $\mathrm{Al}_{x} \mathrm{CoCrFeNi}$ with $x$ variation from 0 to
Table 2 The enthalpy data for empirical rules calculations used in the present work. The mol refers to mol of atoms

\begin{tabular}{|c|c|c|}
\hline & $\Delta H_{A, B}^{\mathrm{mix}}(\mathrm{a}), \mathrm{kJ} \mathrm{mol}^{-1}$ & $\Delta H_{\mathrm{IM}}(\mathrm{b}), \mathrm{kJ} \mathrm{mol}^{-1}$ \\
\hline Al-Co & -19 & -60.69 \\
\hline $\mathrm{Al}-\mathrm{Cr}$ & -10 & -13.31 \\
\hline $\mathrm{Al}-\mathrm{Fe}$ & -11 & -35.60 \\
\hline $\mathrm{Al}-\mathrm{Li}$ & -4 & -18.53 \\
\hline Al-Mg & -2 & -3.18 \\
\hline Al-Mn & -19 & -26.82 \\
\hline $\mathrm{Al}-\mathrm{Ni}$ & -22 & -65.32 \\
\hline Al-Sn & 4 & 0 \\
\hline $\mathrm{Al}-\mathrm{Zn}$ & 1 & -50.17 \\
\hline $\mathrm{Co}-\mathrm{Cr}$ & -4 & 0.48 \\
\hline $\mathrm{Co}-\mathrm{Fe}$ & -1 & -5.79 \\
\hline Co-Mn & -5 & -1.83 \\
\hline $\mathrm{Co}-\mathrm{Ni}$ & 0 & -2.03 \\
\hline $\mathrm{Cr}-\mathrm{Fe}$ & -1 & -0.77 \\
\hline $\mathrm{Cr}-\mathrm{Ni}$ & -7 & -2.89 \\
\hline Cr-Mn & -2 & -10.61 \\
\hline Fe-Mn & 0 & 0.87 \\
\hline $\mathrm{Fe}-\mathrm{Ni}$ & -2 & -9.36 \\
\hline $\mathrm{Li}-\mathrm{Mg}$ & 0 & -6.175 \\
\hline $\mathrm{Li}-\mathrm{Sn}$ & -18 & -41.97 \\
\hline $\mathrm{Li}-\mathrm{Zn}$ & -7 & -21.42 \\
\hline $\mathrm{Mg}-\mathrm{Sn}$ & -9 & -21.42 \\
\hline $\mathrm{Mg}-\mathrm{Zn}$ & -4 & -13.41 \\
\hline Ni-Mn & -8 & -11.10 \\
\hline Sn-Zn & 1 & 0 \\
\hline
\end{tabular}

(a)Values taken from Ref 36

(b)Values taken from Ref 17, for the value contains Li or Sn, which are not included in Ref 17, are taken from OQMD (http://oqmd.org/) ${ }^{[39]}$

2. Just below the solidus temperature the temperature-concentration section can be divided into four solid phase regions: the Fcc single phase region with $x<0.52$; the $\mathrm{Fcc}+\mathrm{B} 2$ two phase region with $0.52<x<0.72$; the $\mathrm{Fcc}+\mathrm{B} 2+\mathrm{Bcc}$ three phase region with $0.72<x<1.35$; and the $\mathrm{B} 2+\mathrm{Bcc}$ two phase region with $1.35<x<2$. For these alloys, the HEA/CCA interface corresponds to the phase boundary between Fcc single phase region and $\mathrm{Fcc}+\mathrm{B} 2$ two phase region. The $\sigma$ phase is also formed in some regions at a temperature lower than $900{ }^{\circ} \mathrm{C}$, but in the present work we will only consider the solid phases just below the solidus temperature, and will not discuss the $\sigma$ phase and other intermetallic phases formed at low temperature.

Figure 1(b) represents the relationship of Al content $x$ with the empirical rules parameters based on Hume-Rothery rules, i.e., the parameters of $\delta_{\mathrm{r}}{ }^{[10]} \gamma,{ }^{[15]} \Delta \chi,{ }^{[16]} \mathrm{VEC},{ }^{[9]}$ and $\Lambda .{ }^{[21]}$ The $\delta_{\mathrm{r}}$ value increases with the increase of $\mathrm{Al}$ content, which indicates that the $\mathrm{Al}$ addition reduces the stability of the DSS 


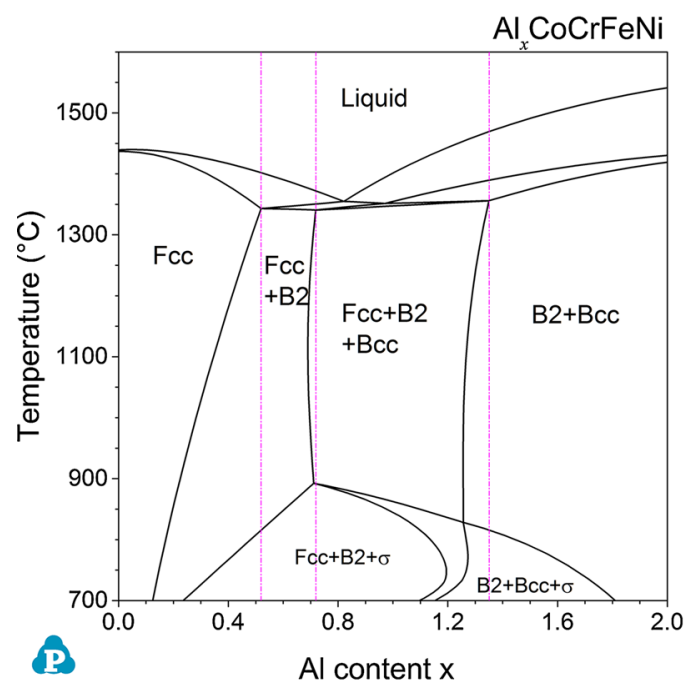

(a)

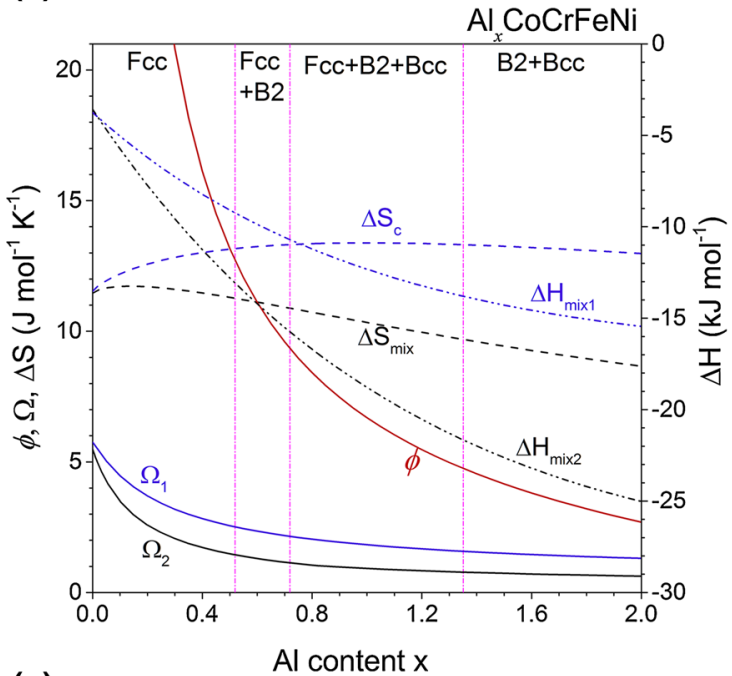

(c)

Fig. 1 The $\mathrm{Al}_{x} \mathrm{CoCrFeNi}$ system with $x$ variation from 0 to 2: (a) Calphad calculated temperature-composition section phase diagram, (b)-(d) The values of parameters based on empirical rules. The meaning of the parameters in empirical rules is explained in section 2 . In Fig. 1(c), two sets of curves are provided for $\Delta S, \Delta H_{\text {mix }}$ and $\Omega$ :

phase and intermetallic phases tend to be formed in higher $\mathrm{Al}$ content. According to the phase diagram shown in Fig. 1(a), the highest $x$ value for HEA/CCA interface is $x=0.52$ at the solidus temperature, where $\delta_{\mathrm{r}}=4.28$. The $\delta_{\mathrm{r}}$ value for all $\mathrm{Al}_{x} \mathrm{CoCrFeNi}$ alloys with $x<2$ are less than the critical value of $\delta_{\mathrm{r}}=6.6$ proposed in Ref 10 .

Unlike the $\delta_{\mathrm{r}}$, which shows clear variation with increasing $\mathrm{Al}$ content, another atomic size difference parameter $\gamma^{[15]}$ is almost constant near 1.158 (from 1.157 to 1.160) for alloys from $\mathrm{Al}_{0} \mathrm{CoCrFeNi}$ to $\mathrm{Al}_{2} \mathrm{CoCrFeNi}$. Based on the critical condition of $\gamma<1.175$ suggested in Ref 15 all $\mathrm{Al}_{x} \mathrm{CoCrFeNi}$ alloys $(x<2)$ satisfy the conditon; they have the same level of potential on the formation of DSS phase, while the Calphad phase diagram shown in Fig. 1(a) indicates that four different

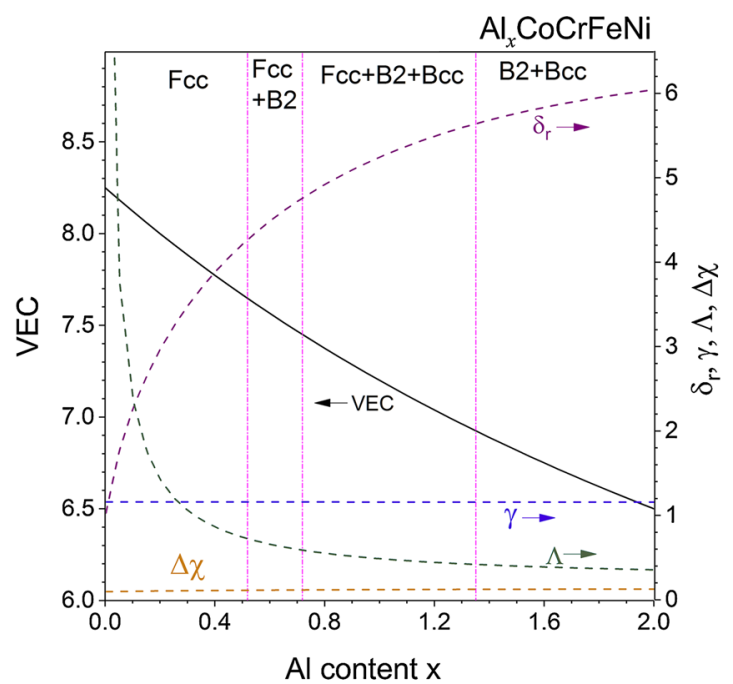

(b)

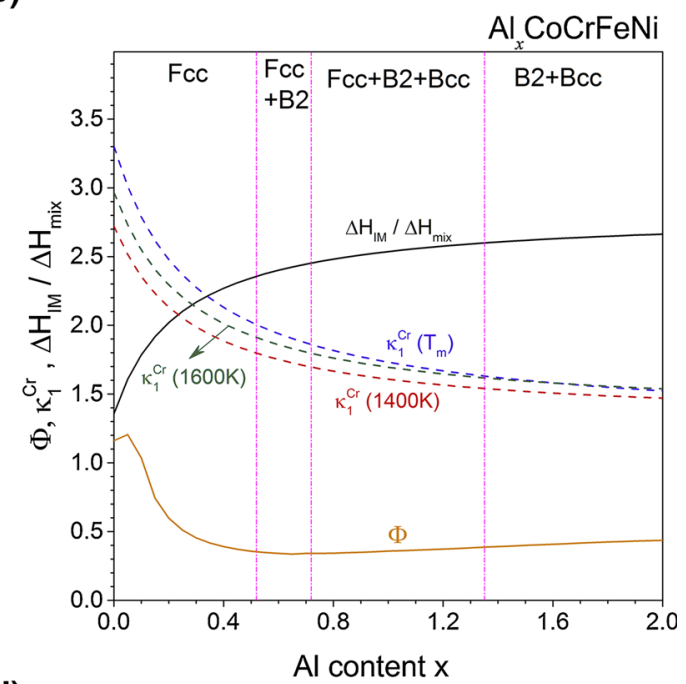

(d)

$\Delta S_{\mathrm{c}}, \Delta H_{\mathrm{mix} 1}$ and $\Omega_{1}$ are calculated based on the equations proposed in Ref 10, which are often used as empirical rules. $\Delta S_{\text {mix }}, \Delta H_{\text {mix } 2}$ and $\Omega_{2}$ are obtained based on current Calphad calculations using the consistent thermodynamic databases

phase regions exist in this composition range of the alloys. From this point of view, this parameter $\gamma$ is considered not superior to or even less effective than $\delta_{\mathrm{r}}$.

With the value $x$ in $\mathrm{Al}_{x} \mathrm{CoCrFeNi}$ increasing from 0 to 2, the $\Delta \chi$ value increases from 0.099 to 0.127 , which is within the suggested region of $0.1-0.15$ in Ref 16 for the formation of HEAs. The VEC value decreases from 8.25 to 6.5 . VEC $>7.65$ is Fcc single phase, VEC between 7.65 and 7.45 is $\mathrm{Fcc}+\mathrm{B} 2$ two phase region, 7.45 and 6.92 is $\mathrm{Fcc}+\mathrm{B} 2+\mathrm{Bcc}$ three-phase region; and a VEC value $<6.92$ is $\mathrm{Bcc}+\mathrm{B} 2$ two phase region. Based on the current Calphad calculation, the Fcc single phase region forms when $\Lambda>0.73$, which is less than critical value of 0.95 proposed in Ref 21 . 
Figure 1(c) shows the variation of several empirical parameters, associated with thermodynamic properties, with the amount of $x$ in $\mathrm{Al}_{x} \mathrm{CoCrFeNi}$ alloys. Two entropy values, i.e., the configurational entropy of the alloy $\Delta S_{\mathrm{c}}$ and Calphad calculated mixing entropy $\Delta S_{\text {mix }}$, are presented. The $\Delta S_{\mathrm{c}}$ value reaches maximum value of 13.382 at $x=1$, where $\mathrm{Fcc}+\mathrm{B} 2+\mathrm{Bcc}$ three phases are stable at the solidus temperatures. But $\Delta S_{\text {mix }}$ reaches its maximum value of 11.727 at $x=0.15$, where the Fcc phase is the only stable phase at temperatures just below the solidus. Two enthalpy of mixing values $\Delta H_{\text {mix }}$ are also presented: the $\Delta H_{\text {mix } 1}$ refers to the enthalpy of mixing value calculated based on the Miedema's model as described in section 2.2.2, which is widely used as an empirical rule ${ }^{[8-10,12]}$; the $\Delta H_{\text {mix } 2}$ refers to the enthalpy of mixing values by the

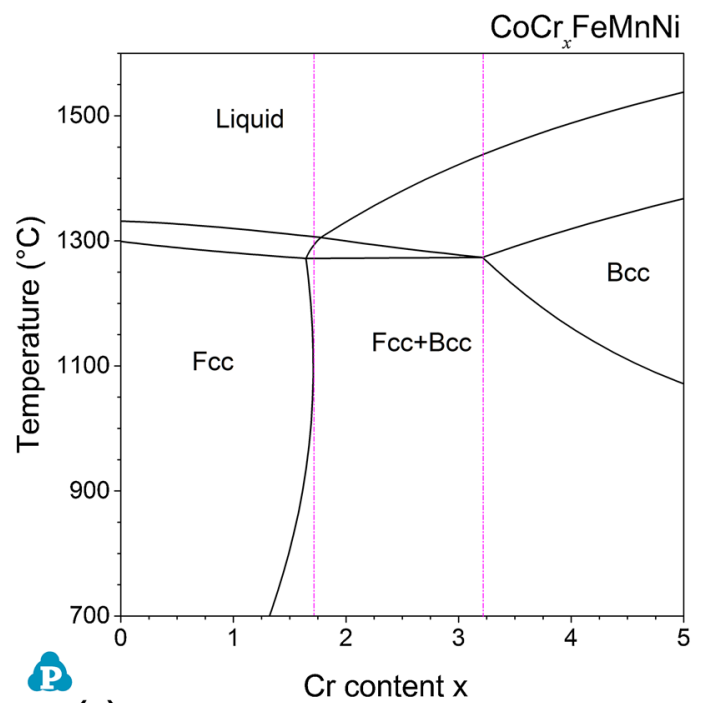

(a)

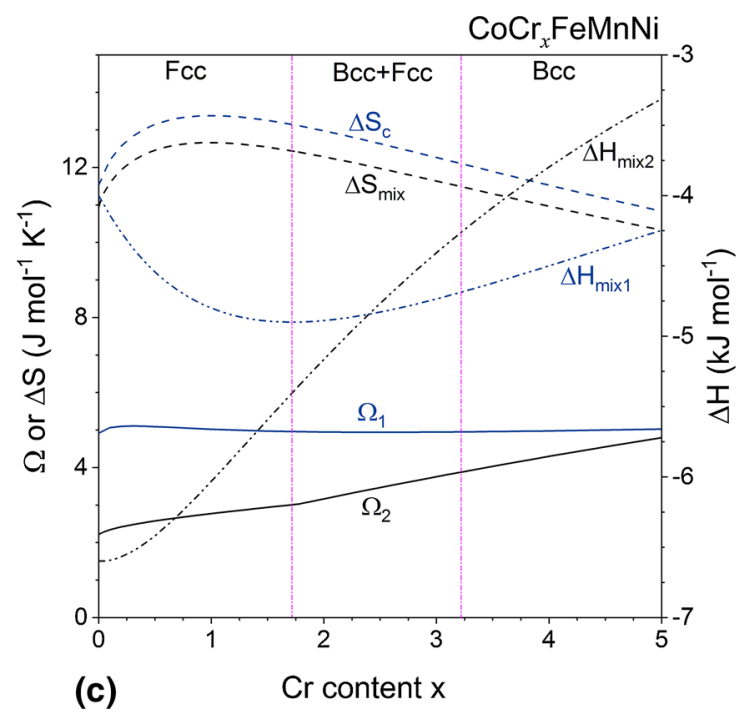

Fig. 2 The $\mathrm{CoCr}_{x} \mathrm{FeMnNi}$ system with $x$ variation from 0 to 5 : (a) Calphad calculated temperature-composition section phase diagram, (b)-(d) The values of parameters based on empirical rules. The present Calphad calculations at the liquidus temperatures of the alloys. Both $\Delta H_{\text {mix }}$ decrease with increasing the value of $x$ from 0 to 2 , but the $\Delta H_{\text {mix } 2}$ value decreases more significantly than the decrease of the $\Delta H_{\text {mix } 1}$ value.

Based on the two entropy and enthalpy values, two $\Omega$ parameter values are also obtained. The $\Omega_{1}$ is following the empirical rule as treated in Ref 10 and described in section 2.2.3. The $\Omega_{1}$ values are calculated based on equation: $\Omega_{1}=\frac{T_{m} \Delta S_{c}}{\mid{ }^{\Delta H_{\text {mix } 1} \mid}}$ in which $T_{m}=\sum_{i=1}^{N} c_{i}\left(T_{m}\right)_{i}$. The $\Omega_{2}$ are based on the Calphad calculation in this work, with $\Omega_{2}=$ $\frac{T_{m} \Delta S_{\operatorname{mix}}}{\left|\Delta H_{\text {mix } 2}\right|}$ in which $T_{m}$ is the Calphad calculated liquidus temperature of the alloys, which is shown in Fig. 2(a). The

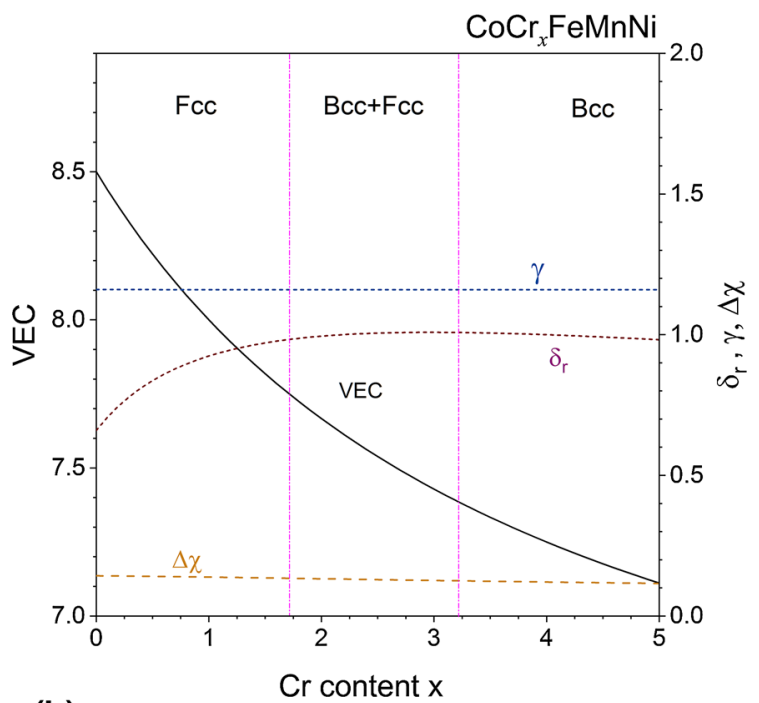

(b)

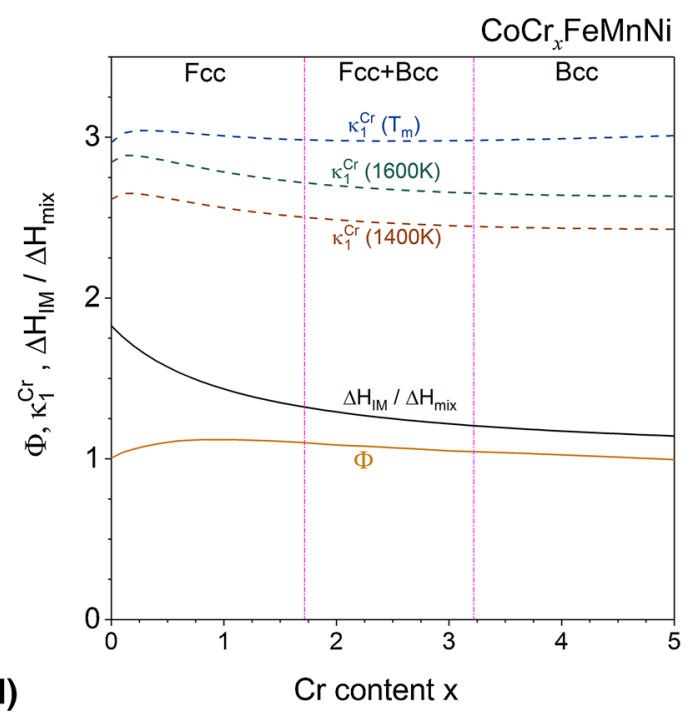

meaning of the parameters in empirical rule is explained in section 2 . The methods used to determine the value of two $\Delta S, \Delta H_{\text {mix }}$ and $\Omega$ parameter in (c) are the same as in Fig. 1(c) 
$\Omega_{2}$ value is lower than the $\Omega_{1}$ value in all alloys. The critical value of $\Omega_{2}$ for limit of Fcc single phase region is 1.4 , and of $\Omega_{1}$ is 2.5 .

The values obtained for the parameter $\phi$ proposed in Ref 19 (section 2.2.4) are also presented in Fig. 1(c). With increasing $\mathrm{Al}$ content, the $\phi$ value decreases greatly. When $\phi<12.8$, which is less than the proposed value of 20 in Ref 19, the $\mathrm{Al}_{x} \mathrm{CoCrFeNi}$ alloy transforms from Fce single phase region to $\mathrm{Fcc}+\mathrm{B} 2$ two phase region.

Figure 1(d) shows two parameters $\Phi^{[20]}$ and $\kappa \cdot{ }^{[11]}$ Both parameters are associated with the Gibbs energy of different phases, and their values were obtained from empirical methods and simplifications. ${ }^{[11,20]}$ It was proposed that a value of $\Phi>1$ suggests a stable solid solution at the alloy's solidus temperature. ${ }^{[20]}$ With increasing $x$ from 0 to 2 in the $\mathrm{Al}_{x} \mathrm{CoCrFeNi}$ alloys, the $\Phi$ value first increases and then decreases. The $\Phi$ value is lower than 1 when $x>0.1$. For the $\kappa$ parameter, the intersection points of the $\kappa_{1}^{\text {cr }}$ (T) curves with the $\Delta H_{\mathrm{IM}} / \Delta H_{\mathrm{SS}}$ curve shown in Fig. 1(d) are critical points where $\Delta H_{\mathrm{IM}} / \Delta H_{\mathrm{SS}}=\kappa_{1}^{\text {cr }}(T)$. When $\mathrm{Al}$ content in the alloy is less than the critical value, the condition $\Delta H_{\mathrm{IM}} / \Delta H_{\mathrm{SS}}<\kappa_{1}^{\mathrm{cr}}(T)$ is satisfied which predicts the formation of a single solid solution phase structure. ${ }^{[11]}$ The values determined from Fig. 1(d) are $x=0.34$ at liquidus temperature $T_{\mathrm{m}}, x=0.29$ at $1600 \mathrm{~K}$ and $x=0.23$ at $1400 \mathrm{~K}$. But all these values are lower than the Calphad calculated value of 0.52 .

\subsection{Co-Cr-Fe-Mn-Ni System}

The equiatomic CoCrFeMnNi alloy with single Fcc phase was first produced by Cantor et al. ${ }^{[1]}$ Figure 2 shows the phase diagram of $\mathrm{CoCr}_{x} \mathrm{FeMnNi}$ system and the evolution of parameters from empirical rules with the variation of $x$ from 0 to 5. According to the Calphad calculated phase diagram of $\mathrm{CoCr}_{x} \mathrm{FeMnNi}$ system as shown in Fig. 2(a), the $\mathrm{CoCr}_{x} \mathrm{FeMnNi}$ alloys transform from Fcc single phase alloy structure to Bcc $+\mathrm{Fcc}$ two phase structure and then to $\mathrm{Bcc}$ single phase structure again with increasing $\mathrm{Cr}$ content $x$ from 0 to 5 . When $x<1.71$, it is a Fcc single phase structure at $1100{ }^{\circ} \mathrm{C}$. When $x$ is between 1.71 and 3.21, two phases, Fcc + Bcc, are stable in the alloys. A stable Bcc single phase region appears at temperature between 1100 and $1300{ }^{\circ} \mathrm{C}$ when $x>3.21$.

Figure 2(b) shows the variation of the parameters of $\delta_{\mathrm{r}}$, $\gamma, \Delta \chi$ and VEC, associated with the $\mathrm{Cr}$ content $x$ in $\mathrm{CoCr}_{x} \mathrm{FeMnNi}$ alloys. With $\mathrm{Cr}$ amount of $x$ increasing from 0 to 5 , the $\Delta \chi$ value decreases from 0.143 to 0.116 , and the VEC value from 8.5 to 7.1. All these alloys are predicted to be HEAs with $\Delta \chi$ value between 0.1 and $0.15,{ }^{[16]}$ which contradicts with the present Calphad calculation. The Fcc single phase region corresponds to $\mathrm{VEC}>7.75$, and the $\mathrm{Fcc}+\mathrm{Bcc}$ two-phase region to $\mathrm{VEC}<7.75$. When
VEC $<7.38$, the Bcc single phase region can also be stable at high temperature as shown in Fig. 2(a). Although it was claimed that VEC rule did not fit for Mn-containing alloys, ${ }^{[9]}$ the VEC values qualitatively agree with the statement in Ref 9. The alloys transform from Fcc single phase structure to $\mathrm{Fcc}+\mathrm{Bcc}$ two phase and Bcc single phase structure with decreasing the VEC values. The critical value of VEC for Fcc/Fcc + Bcc boundary is 7.75 in this work which is close to 8 proposed in Ref 9 . The critical value of VEC for Fcc + Bcc/Bcc boundary is 7.38 in this work instead of 6.87 in Ref 9.

The $\gamma$ value of the $\mathrm{CoCr}_{x} \mathrm{FeMnNi}$ alloys is constant with 1.160 , which is less than the critical value of 1.175 proposed in Ref 15 and favor to form single solid solution phase. The $\delta_{\mathrm{r}}$ value of the alloys varies from 0.66 to 1.01 with variation of $\mathrm{Cr}$ content in the alloys. This value is much smaller than the critical value of 6.6 proposed in Ref 10 From the atomic size effect parameters, $\mathrm{CoCr}_{x} \mathrm{FeMnNi}$ alloys are strongly favorable to have a single solid solution phase.

Figure 2(c) shows the thermodynamic properties parameters obtained by empirical rules and Calphad calculation in this work. The entropy of mixture at liquidus temperature $\left(\Delta S_{\text {mix }}\right)$ obtained by Calphad calculation is less positive than the configurational entropy value $\left(\Delta S_{\mathrm{c}}\right)$. The enthalpy of mixing obtained by empirical rule $\left(\Delta H_{\text {mix } 1}\right)$ is between -4 and $-5 \mathrm{~kJ} \mathrm{~mol}^{-1}$, while the enthalpy of mixing calculated by Calphad approach in this work $\left(\Delta H_{\text {mix } 2}\right)$ is between -3.5 and $-6.5 \mathrm{~kJ} \mathrm{~mol}^{-1}$. The $\Omega$ parameter obtained by empirical rules $\left(\Omega_{1}\right)$ is between 4.9 and 5.0, while the value by Calphad calculations is between 2.2 to 4.8 . Using the enthalpy, entropy and $\Omega$ values obtained by both methods in the corresponding empirical rules they all predict $\mathrm{CoCr}_{x} \mathrm{FeMnNi}$ alloys as single phase HEAs in contrast to Fig. 2(a).

The course of parameters $\kappa_{1}^{\mathrm{cr}}(T)$ and $\Phi$ with variation of $\mathrm{Cr}$ content $x$ in $\mathrm{CoCr}_{x} \mathrm{FeMnNi}$ alloys is shown in Fig. 2(d). The $\kappa_{1}^{\text {cr }}\left(T_{\mathrm{m}}\right)$ value is always higher than $\Delta H_{\mathrm{IM}} / \Delta H_{\mathrm{SS}}$, which indicates the formation of single solid solution phase is preferred as suggested in Ref 11 . The value of $\Phi$ is about 1.0 to 1.1 for all these alloys, which is slightly higher than the critical value of 1.0 for the formation of single solid solution phase proposed in Ref 20.

For these alloys, the $\Lambda$ values are between 27 and 11, which are much higher than the critical value of 0.95 proposed in Ref 21 thus based on this rule, the entire composition range of this alloys should be always in single DSS phase, again in contrast to Fig. 2(a). The same applies for the parameter $\phi$, which varies from 674 to 300 for $\mathrm{CoCr}_{x} \mathrm{FeMnNi}$ alloys, much higher than the critical value of 20 in Ref 19. The values of $\Lambda$ and $\phi$ obtained here are much higher than the suggested critical values for $\mathrm{CoCr}_{x-}$ $\mathrm{FeMnNi}$ alloys, and, therefore, are not presented in any of the diagrams here. 


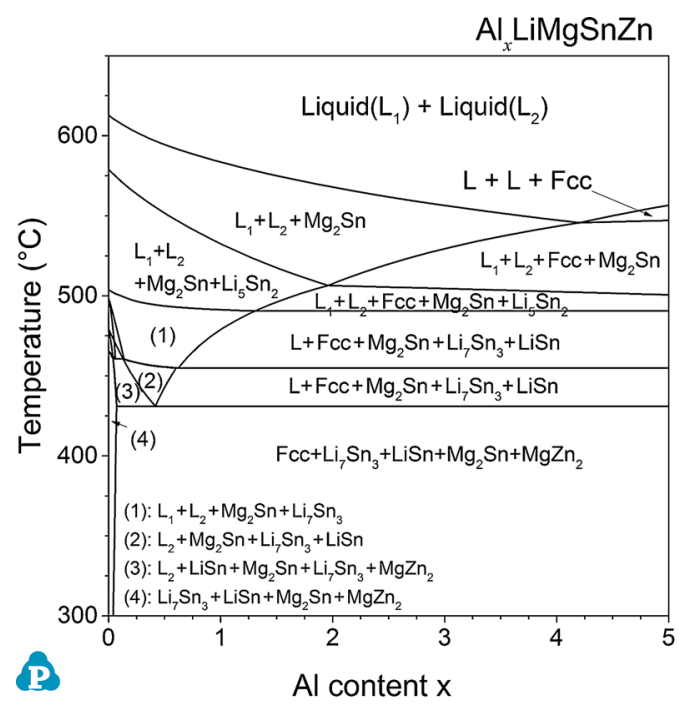

(a)

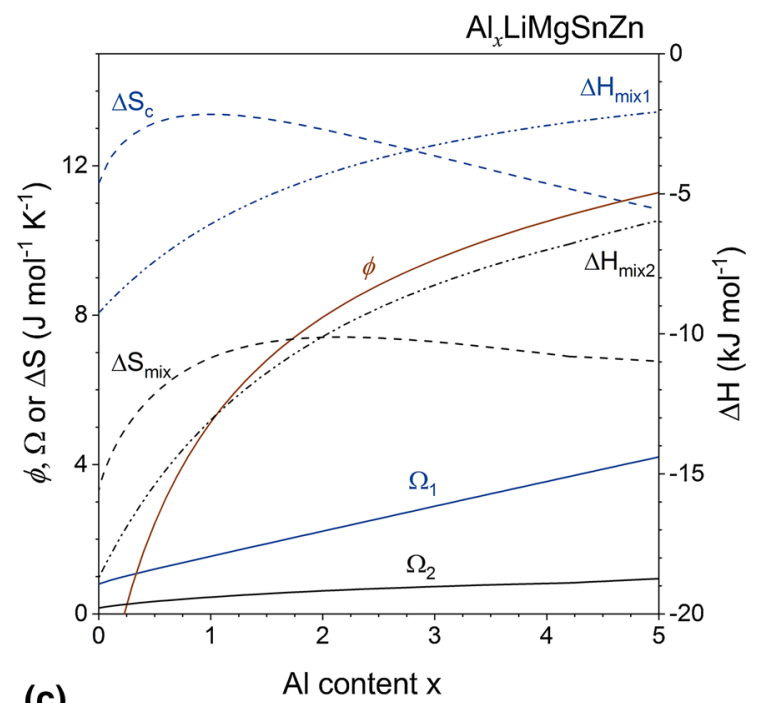

(c)

Fig. 3 The $\mathrm{Al}_{x} \operatorname{LiMgSnZn}$ system with $x$ variation from 0 to 5: (a) Calphad calculated temperature-composition section phase diagram, (b)-(d) The values of parameters based on empirical rules. The

For all the $\mathrm{CoCr}_{x} \mathrm{FeMnNi}$ alloys with $x$ between 0 and 5 all parameters values based on empirical rules, except the VEC, predict HEAs with single solid solution phase. The main problem is that the empirical rules did not distinguish the single solid solution phases as Bcc, Fcc or Hcp, thus they failed to predict the wide two-phase region $\mathrm{Fcc}+\mathrm{Bcc}$ in this case.

\subsection{Al-Li-Mg-Sn-Zn System}

In order to explore low-density MPEAs, several works ${ }^{[16,51,52]}$ have been done on light weight elements such as, $\mathrm{Li}, \mathrm{Mg}$ and $\mathrm{Al}$. One published example is the AlLi-Mg-Sn-Zn system. ${ }^{[16]}$ In the present work, we use

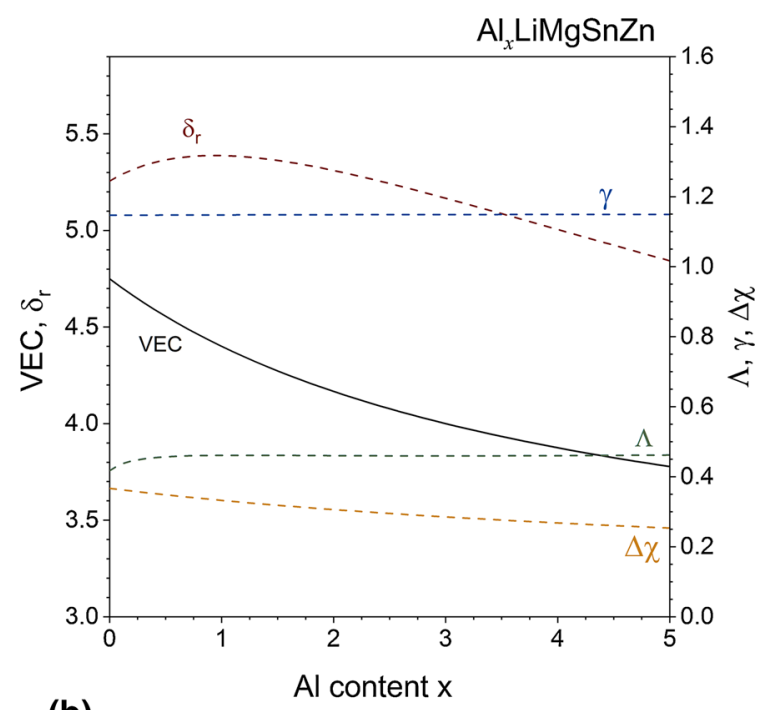

(b)

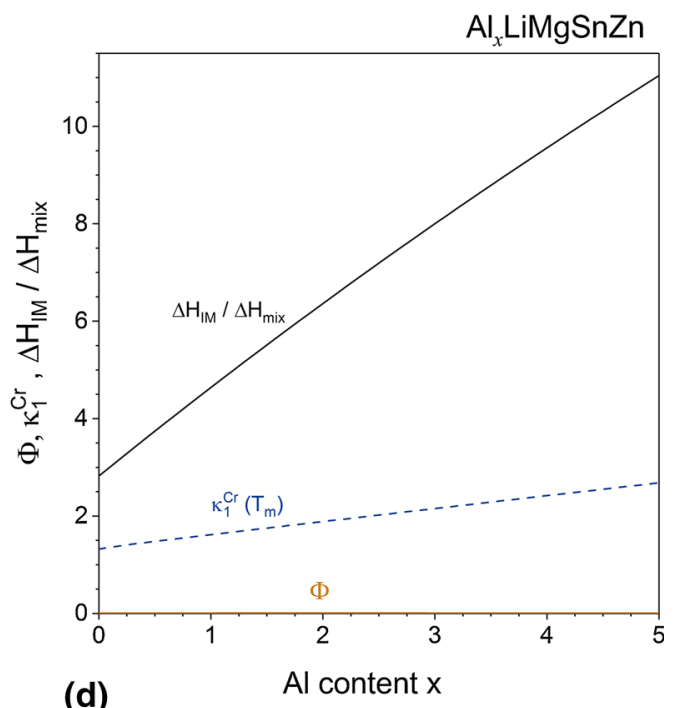

meaning of the parameters in empirical rule is explained in section 2 . The methods used to determine the value of two $\Delta S, \Delta H_{\text {mix }}$ and $\Omega$ parameter in (c) are the same as in Fig. 1(c)

$\mathrm{Al}_{x} \mathrm{LiMgSnZn}$ alloys with $x$ from 0 to 5 as an example to compare the Calphad calculations and the empirical rule parameters. The Calphad calculated phase diagram and empirical parameter values are shown in Fig. 3 .

Figure 3(a) represents the Calphad calculated phase diagram of the $\mathrm{Al}_{x} \mathrm{LiMgSnZn}$ section with $x$ from 0 to 5 . Two multiphase regions, shown in Fig. 3(a), are below the solidus line: one contains $\mathrm{Li}_{7} \mathrm{Sn}_{3}+\mathrm{LiSn}+\mathrm{Mg}_{2}$ $\mathrm{Sn}+\mathrm{MgZn}_{2}$, four solid phases; the other contains $\mathrm{Fcc}+\mathrm{Li}_{7} \mathrm{Sn}_{3}+\mathrm{LiSn}+\mathrm{Mg}_{2} \mathrm{Sn}+\mathrm{MgZn}_{2}, \quad$ five solid phases. With increasing $\mathrm{Al}$ content, the amount of Fcc phase increases, but other intermetallic phases still exist. This result indicates that $\mathrm{Al}_{x} \mathrm{LiMgSnZn}$ system is not suitable for developing HEAs or CCAs. 
The calculated phase diagram shows two liquid phases coexisting, one is enriched with $\mathrm{Li}$ and $\mathrm{Sn}$ (L1), and the other is enriched with $\mathrm{Al}, \mathrm{Mg}, \mathrm{Zn}$ (L2). This is a result of the thermodynamic modeling of liquid phase and has not been justified by experimental work. But one can not excluded the existence of the miscibility gap in the liquid phase either, with considering the existence of miscibility gap in Mg-Al-Sn ternary system ${ }^{[53]}$ and the experimentally detected existence of short-range ordering in Li-Sn binary system. ${ }^{[54,55]}$ Although the reliability of the database for Al-Li-Mg-Sn-Zn quinary system has not been verified by any five-component system, all the binary sub-systems have been thermodynamically assessed and properly modeled. Some discrepancy with the experimental results may exist regarding the formation of some more stable ternary phases which are not included in the current used $\mathrm{Mg}$ database. For example, the $\mathrm{Li}_{2} \mathrm{MgSn}$ phase was experimentally detected in Ref 16 , rather than the binary intermetallic phases shown in Fig. 3(a). Nevertheless, the Calphad calculation is still considered superior to the empirical rules, which only considered the simplified interaction effects of binary systems.

Figure 3(b) shows the relationship of parameters VEC, $\Delta \chi, \delta_{\mathrm{r}}, \gamma$ and $\Lambda$ with $\mathrm{Al}$ content $x$ in $\mathrm{Al}_{x} \mathrm{LiMgSnZn}$ alloys. With increase of $\mathrm{Al}$ content from 0 to 5, the VEC value decreases from 4.75 to 3.78 ; the $\Delta \chi$ value decreases from 0.367 to 0.254 ; the $\delta_{\mathrm{r}}$ value varies between 5.40 and 4.84 ; the $\gamma$ value is almost constant with 1.15 ; and the $\Lambda$ value varies between 0.417 and 0.462 . If we follow the empirical rules, the $\Delta \chi$ and $\Lambda$ parameters predict the formation of light weight CCAs, but the obtained values of the parameters of $\delta_{\mathrm{r}}$ and $\gamma$ of $\mathrm{Al}_{x} \mathrm{LiMgSnZn}$ alloys are all less than the critical values and predict the formation of single solid solution phase structure, in contrast to the Calphad calculations in this work and experimental results. ${ }^{[16]}$

Figure 3(c) represents the thermodynamic properties based on empirical rules and Calphad calculations. The maximum value of entropy of mixing $\left(\Delta S_{\text {mix }}\right)$ at liquidus temperature by Calphad calculation is $7.4 \mathrm{~J} \mathrm{~mol}^{-1} \mathrm{~K}^{-1}$ at $x=2.1$, which is much lower than the maximum value of configurational entropy of mixing of $13.38 \mathrm{~J} \mathrm{~mol}^{-1} \mathrm{~K}^{-1}$ at $x=1$, thus no longer a high entropy system. The Calphad calculated enthalpy of mixing $\left(\Delta H_{\mathrm{mix} 2}\right)$ at the liquidus temperature is also much more negative than the enthalpy of mixing calculated from empirical rules $\left(\Delta H_{\text {mix } 1}\right)$. As a result, the Calphad calculated parameter $\Omega_{2}$ is less than the empirical rule calculated parameter $\Omega_{1}$. Following the prediction method in Ref 10 , the obtained $\Omega_{1}$ value is higher than the critical value of 1.1 , and only one single DSS phase is expected. But if we use the Calphad calculated $\Omega_{2}$, which is between 0.16 and 1.0 , less than the critical value of 1.1, and intermetallic phases are expected, as shown in fact in Fig. 3(a).
The $\phi$ value of $\mathrm{Al}_{x} \mathrm{LiMgSnZn}$ alloys increases with increasing $\mathrm{Al}$ content as shown in Fig. 3(c), but the $\phi$ value is always less than 12 , much less the critical value of 20 proposed in Ref 19. This result predicts the formation of multi-phase structure in $\mathrm{Al}_{x} \mathrm{LiMgSnZn}$ alloys.

Figure 3(d) shows that the $\kappa_{1}^{\text {cr }}\left(T_{\mathrm{m}}\right)$ value is always less than $\Delta H_{\mathrm{IM}} / \Delta H_{\mathrm{SS}}$, and the $\Phi$ value is close to zero. Both parameters predict that intermetallic phases will be formed in this alloy system, which is consistent with Calphad calculations and experimental results.

\section{Discussion}

\subsection{The Source of the Atomic Size}

The atomic size difference is considered as the fundamental condition on the formation of DSS phases, thus many empirical rule parameters, such as $\delta_{\mathrm{r}}, \gamma, \Delta S_{\mathrm{E}}, \phi$ and $\Lambda$ are essentially determined by the atomic size of the elements as component of the alloy. Although the value of the atomic radii of the element is so important for these parameters, none of the paper described in detail which atomic radii values were adopted in their calculations. Actually, the atomic radius value is not so well defined and determined. The webelement website, ${ }^{[46]}$ which is the source for Ref 7, 9, and 56 states "The size of the neutral atoms depends upon the way in which the measurement is made and the environment. The term 'atomic radius' is not particularly helpful although its use is widespread. The problem is its meaning, which is clearly very different in different sources and books".

The atoms in solid materials are held through three types of bonding: Covalent bonding, ionic bonding and metallic bonding. ${ }^{[57]}$ Correspondingly, the atomic radius can be covalent radius, ionic radius, and metallic radius. ${ }^{[47]}$ Based on the bonding theory for metals and alloys assumption in Ref 57, covalent bond and metallic bond coexist in metals and alloys, no metal or alloy can be $100 \%$ metallic bond or $100 \%$ covalent bond. Thus, it is controversial to use covalent radius value or metallic radius value for describing the atomic size differences. Fang et al. ${ }^{[58]}$ used the $\delta_{\mathrm{r}}$ parameter for Mg-based bulk metallic glasses prediction and they accepted the covalent atomic radius to elements. Zhang et al. ${ }^{[8]}$ firstly proposed the $\delta_{\mathrm{r}}$ parameter citing from Ref 58 to predict the phase stability of MPEAs, but they ${ }^{[8]}$ referred the atomic radii data to Ref 59 an earlier version of Ref 47. In, Ref 47 Kittel suggested three types of atomic radius, i.e., standard radii for ions in inert gas (ionic atomic radius), radii of atoms when in tetrahedral covalent bonds (covalent atomic radius) and radii of ions in 12-coordinated metals (metallic atomic radius). But in Ref 8 it is not mentioned which values were adopted in their prediction. 
Table 3 The impact of atomic radii data in different sources on the dimensionless parameter of $\delta_{\mathrm{r}}, \gamma, \phi$ and $\Lambda$ for the equiatomic $\mathrm{CoCr}$ FeMnNi alloy

\begin{tabular}{lcccc}
\hline Sources & $\delta_{\mathrm{r}}$ & $\gamma$ & $\phi$ & $\Lambda$ \\
\hline [This work] & 0.92 & 1.1599 & 389 & 15.671 \\
[2017Mir] & 3.27 & 1.1596 & 30 & 1.25
\end{tabular}

[This work]: all radii data are from the metallic radius value in Ref 47 [2017Mir]: radii data are from the value provided in Ref 7

The atom radius values in Ref 7 are from Ref 56 where the atomic radii were used to predict the glass forming ability of amorphous metallic alloys. In Ref 56 three sources $^{[46,60,61]}$ were provided for different elements. Most of radii values in Ref 56 are close or identical to the values of the metallic atomic radii in Ref 47 , but some show significant differences.

A typical example is the element manganese. The covalent atomic radius value in Ref 58 is 146 pm, metallic atomic radius in Ref 47 is $126 \mathrm{pm}$, and atomic radius in Ref 7 and 56 is 135 pm cited from webelements website in year 2000. However, in 2017 the current webelement website $^{[46]}$ provides a value of $140 \mathrm{pm}$ for empirical atomic radius, $161 \mathrm{pm}$ for calculated atomic radius, and $139 \mathrm{pm}$ for covalent atomic radius. The difference between the smallest value of $126 \mathrm{pm}$ and largest value of $161 \mathrm{pm}^{[46]}$ is $35 \mathrm{pm}$, which is more than $20 \%$ of the atomic size value. Table 3 shows the impact of different radii source on the parameter for the equiatomic $\mathrm{CoCrFeMnNi}$ alloy. The value of the parameters show significant differences especially for the parameters $\phi$ and $\Lambda$.

\subsection{Discussion on Different Empirical Rule Parameters}

The atomic size difference parameter $\delta_{\mathrm{r}}$ provides a very simple rule, but the condition of $\delta_{\mathrm{r}}<6.6$ can only be considered as a necessary condition for the formation single solid solution phase structure. In this work, all the calculated alloys satisfy this condition, but the single solid solution phase only exist in some regions of $\mathrm{Al}_{x} \mathrm{CoCrFeNi}$ and $\mathrm{CoCr}_{x} \mathrm{FeMnNi}$ alloys. The $\mathrm{Al}_{x} \mathrm{LiMgSnZn}$ alloys also fit the condition $\delta_{\mathrm{r}}<6.6$, but the intermetallic phases are the dominant phases. Compared to the parameter $\delta_{\mathrm{r}}$, another atomic size parameter, $\gamma$, is even less effective. The variation of $\gamma$ with alloy composition in the three alloy systems investigated in this work is almost undetectable, for $\mathrm{Al}_{x}$ CoCrFeNi varies from 1.157 to $1.160, \mathrm{CoCr}_{x} \mathrm{FeMnNi}$ keeps constant at 1.160 , and $\mathrm{Al}_{x} \mathrm{LiMgSnZn}$ from 1.147 to 1.149. The tiny differences between alloys and even different alloy systems cannot provide useful prediction on the formation of the phases.
The VEC values for $\mathrm{Al}_{x} \mathrm{CoCrFeNi}$ and $\mathrm{CoCr}_{x} \mathrm{FeMnNi}$ alloys are between 8.5 and 6.5, Fcc phase appears at higher values while Bcc phase at lower values. The VEC values for $\mathrm{Al}_{x} \mathrm{LiMgSnZn}$ alloys are between 4.75 and 3.78 , but intermetallic phases always appear in these alloys while the amount of Fcc phase increases with decreasing VEC.

The comparison of the Calphad calculated thermodynamic properties with the values obtained by empirical rules indicates that the simplification of configurational entropy of mixing for entropy of mixing of the solid solution phases may generate large deviation, especially for alloys contain light weight elements, such as the AlLiMgSnZn alloys in this work. The high entropy effect is not the key factor for the formation of the single solid solution phase. The parameter $\Omega$ obtained from the thermodynamic data by Calphad calculations provides better prediction than the value calculated from the method suggested in the original paper. ${ }^{[10]}$

The $\kappa$ and $\Phi$ parameters provide the most reliable predictions for $\mathrm{Al}_{x} \mathrm{CoCrFeNi}$ and $\mathrm{Al}_{x} \mathrm{LiMgSnZn}$ systems, but both methods also require complicated calculations. and they failed to find the transformation from Fcc to Bcc single phase regions in $\mathrm{CoCr}_{x} \mathrm{FeMnNi}$ system.

\subsection{Reliability of the Thermodynamic Database Used in Calphad Calculations}

In the present work, we used PanHEA database for Al-Co$\mathrm{Cr}-\mathrm{Fe}-\mathrm{Ni}$ and Co-Cr-Fe-Mn-Ni systems, and MgDB database for Al-Li-Mg-Sn-Zn system.

The PanHEA database contains the full thermodynamic descriptions on all the binary and ternary sub-systems of AlCoCrFeNi and CoCrFeMnNi systems, and the reliability of these systems has also been validated and discussed in Ref 22-25. In the currently used $\mathrm{Mg}$ database ${ }^{[44]}$ for AlLiMgSnZn system calculations, all the binary sub-systems and the Al-Li-Mg, Al-Mg-Sn, Al-Mg-Zn, Al-Sn-Zn, $\mathrm{Li}-\mathrm{Mg}-\mathrm{Zn}$, and $\mathrm{Mg}-\mathrm{Sn}-\mathrm{Zn}$ ternary subsystems have the full thermodynamic descriptions.

\section{Conclusion}

In this work, we critically reviewed all available empirical rules for prediction the HEA/CCA interface. It is shown that the atomic size data may be quite different in various sources and that may generate significant impact on the values of related parameters, such as $\delta_{\mathrm{r}}, \gamma, \phi$ and $\Lambda$. The effectiveness and limitation of the empirical rules on the selected $\mathrm{Al}_{x} \mathrm{CoCrFeNi}, \mathrm{CoCr}_{x} \mathrm{FeMnNi}$ and $\mathrm{Al}_{x} \mathrm{LiMgSnZn}$ systems have been evaluated based on Calphad calculations, providing validated phase diagrams. The empirical rules can make a reasonable prediction for the 
$\mathrm{Al}_{x} \mathrm{CoCrFeNi}$ system; however, in the $\mathrm{CoCr}_{x} \mathrm{FeMnNi}$ system, most of the empirical rules can not predict the HEA/ CCA interface, specifically the interface between Fcc single-phase structure and $\mathrm{Fcc}+\mathrm{Bcc}$ two-phase structure. For the $\mathrm{Al}_{x} \mathrm{LiMgSnZn}$ system, the parameters of $\delta_{\mathrm{r}}, \gamma$, $\Delta S_{\text {mix } 1}, \Delta H_{\text {mix } 1}$ and $\Omega_{1}$ from empirical rules predict the formation of HEA, though the Calphad calculations and experimental results indicate intermetallic phases tend to form in this alloy system. The Calphad approach is considered the benchmark, it can provide a better prediction than empirical rules if all the binary sub-systems have been properly thermodynamically assessed.

\section{References}

1. B. Cantor, I.T.H. Chang, P. Knight, and A.J.B. Vincent, Microstructural Development in Equiatomic Multicomponent Alloys, Mater. Sci. Eng. A, 2004, 375-377, p 213-218

2. J.W. Yeh, S.K. Chen, S.J. Lin, J.Y. Gan, T.S. Chin, T.T. Shun, C.H. Tsau, and S.Y. Chang, Nanostructured High-Entropy Alloys with Multiple Principal Elements: Novel Alloy Design Concepts and Outcomes, Adv. Eng. Mater., 2004, 6(5), p 299-303

3. Y. Zhang, T.T. Zuo, Z. Tang, M.C. Gao, K.A. Dahmen, P.K. Liaw, and Z.P. Lu, Microstructures and Properties of HighEntropy Alloys, Prog. Mater Sci., 2014, 61, p 1-93

4. Z. Li, K.G. Pradeep, Y. Deng, D. Raabe, and C.C. Tasan, Metastable High-Entropy Dual-Phase Alloys Overcome the Strength-Ductility Trade-Off, Nature, 2016, 534(7606), p 227-230

5. W.H. Liu, Z.P. Lu, J.Y. He, J.H. Luan, Z.J. Wang, B. Liu, Y. Liu, M.W. Chen, and C.T. Liu, Ductile CoCrFeNiMox High Entropy Alloys Strengthened by Hard Intermetallic Phases, Acta Mater., 2016, 116, p 332-342

6. B. Schuh, F. Mendez-Martin, B. Völker, E.P. George, H. Clemens, R. Pippan, and A. Hohenwarter, Mechanical Properties, Microstructure and Thermal Stability of a Nanocrystalline CoCrFeMnNi High-Entropy Alloy After Severe Plastic Deformation, Acta Mater., 2015, 96, p 258-268

7. D.B. Miracle and O.N. Senkov, A Critical Review of High Entropy Alloys and Related Concepts, Acta Mater., 2017, 122, p 448-511

8. Y. Zhang, Y.J. Zhou, J.P. Lin, G.L. Chen, and P.K. Liaw, SolidSolution Phase Formation Rules for Multi-component Alloys, Adv. Eng. Mater., 2008, 10(6), p 534-538

9. S. Guo, C. Ng, J. Lu, and C.T. Liu, Effect of Valence Electron Concentration on Stability of FCC or BCC Phase in High Entropy Alloys, J. Appl. Phys., 2011, 109(10), p 103505

10. X. Yang and Y. Zhang, Prediction of High-Entropy Stabilized Solid-Solution in Multi-component Alloys, Mater. Chem. Phys., 2012, 132(2-3), p 233-238

11. O.N. Senkov and D.B. Miracle, A New Thermodynamic Parameter to Predict Formation of Solid Solution or Intermetallic Phases in High Entropy Alloys, J. Alloys Compd., 2016, 658, p 603-607

12. S. Guo and C.T. Liu, Phase Selection Rules for Complex Multicomponent Alloys with Equiatomic or Close-to-Equiatomic Compositions, Chin. J. Nat., 2013, 35(2), p 85-96

13. Y. Zhang, Z.P. Lu, S.G. Ma, P.K. Liaw, Z. Tang, Y.Q. Cheng, and M.C. Gao, Guidelines in Predicting Phase Formation of High-Entropy Alloys, MRS Commun., 2014, 4(2), p 57-62
14. Y. Zhang, X. Yang, and P.K. Liaw, Alloy Design and Properties Optimization of High-Entropy Alloys, JOM, 2012, 64(7), p 830838

15. Z. Wang, Y. Huang, Y. Yang, J. Wang, and C.T. Liu, AtomicSize Effect and Solid Solubility of Multicomponent Alloys, Scr. Mater., 2015, 94, p 28-31

16. X. Yang, S.Y. Chen, J.D. Cotton, and Y. Zhang, Phase Stability of Low-Density, Multiprincipal Component Alloys Containing Aluminum, Magnesium, and Lithium, JOM, 2014, 66(10), p 2009-2020

17. M.C. Troparevsky, J.R. Morris, P.R.C. Kent, A.R. Lupini, and G.M. Stocks, Criteria for Predicting the Formation of SinglePhase High-Entropy Alloys, Phys. Rev. X, 2015, 5(1), p 011041

18. Y.F. Ye, Q. Wang, J. Lu, C.T. Liu, and Y. Yang, The Generalized Thermodynamic Rule for Phase Selection in Multicomponent Alloys, Intermetallics, 2015, 59, p 75-80

19. Y.F. Ye, Q. Wang, J. Lu, C.T. Liu, and Y. Yang, Design of High Entropy Alloys: A Single-Parameter Thermodynamic Rule, Scr. Mater., 2015, 104, p 53-55

20. D.J.M. King, S.C. Middleburgh, A.G. McGregor, and M.B. Cortie, Predicting the Formation and Stability of Single Phase High-Entropy Alloys, Acta Mater., 2016, 104, p 172-179

21. A.K. Singh, N. Kumar, A. Dwivedi, and A. Subramaniam, A Geometrical Parameter for the Formation of Disordered Solid Solutions in Multi-component Alloys, Intermetallics, 2014, 53, p 112-119

22. C. Zhang, F. Zhang, S. Chen, and W. Cao, Computational Thermodynamics Aided High-Entropy Alloy Design, JOM, 2012, 64(7), p 839-845

23. F. Zhang, C. Zhang, S.L. Chen, J. Zhu, W.S. Cao, and U.R. Kattner, An Understanding of High Entropy Alloys from Phase Diagram Calculations, Calphad, 2014, 45, p 1-10

24. C. Zhang, F. Zhang, H. Diao, M.C. Gao, Z. Tang, J.D. Poplawsky, and P.K. Liaw, Understanding Phase Stability of AlCo-Cr-Fe-Ni High Entropy Alloys, Mater. Des., 2016, 109, p $425-433$

25. C. Zhang and M.C. Gao, CALPHAD Modeling of High-Entropy Alloys, High-Entropy Alloys: Fundamentals and Applications, M.C. Gao, J.-W. Yeh, P.K. Liaw, and Y. Zhang, Ed., Springer, Berlin, 2016, p 399-444

26. M.C. Gao, Design of High-Entropy Alloys, High-Entropy Alloys: Fundamentals and Applications, M.C. Gao, J.-W. Yeh, P.K. Liaw, and Y. Zhang, Ed., Springer, Berlin, 2016, p 369-398

27. O.N. Senkov, J.D. Miller, D.B. Miracle, and C. Woodward, Accelerated Exploration of Multi-principal Element Alloys with Solid Solution Phases, Nat. Commun., 2015, 6, p 6529

28. O.N. Senkov, J.D. Miller, D.B. Miracle, and C. Woodward, Accelerated Exploration of Multi-principal Element Alloys for Structural Applications, Calphad, 2015, 50, p 32-48

29. T.B. Massalski, Comments Concerning Some Features of Phase Diagrams and Phase Transformations, Mater. Trans., 2010, 51(4), p 583-596

30. U. Mizutani, Hume-Rothery Rules for Structurally Complex Alloy Phases, CRC Press, Taylor \& Francis Group, London, 2011

31. H. Sato, M. Inukai, E.S. Zijlstra, and U. Mizutani, NFE Approximation for the e/a Determination for 3d-Transition Metal Elements and Their Intermetallic Compounds with $\mathrm{Al}$ and $\mathrm{Zn}$, Philos. Mag., 2013, 93(22), p 3029-3061

32. Y. Zhang, S. Guo, C.T. Liu, and X. Yang, Phase Formation Rules, High-Entropy Alloys: Fundamentals and Applications, M.C. Gao, J.-W. Yeh, P.K. Liaw, and Y. Zhang, Ed., Springer, Berlin, 2016, p 21-49

33. G.A. Mansoori, N.F. Carnahan, K.E. Starling, and T.W. Leland, Equilibrium Thermodynamic Properties of the Mixture of Hard Spheres, J. Chem. Phys., 1971, 54(4), p 1523-1525 
34. F.R. Boer, R. Boom, W.C.M. Mattens, A.R. Miedema, and A.K. Niessen, Cohesion in metals: transition metal alloys, NorthHolland, Amsterdam, 1988

35. A.R. Miedema, P.F. de Châtel, and F.R. de Boer, Cohesion in Alloys-Fundamentals of a Semi-empirical Model, Phys. $B+C$, 1980, 100(1), p 1-28

36. A. Takeuchi and A. Inoue, Classification of Bulk Metallic Glasses by Atomic Size Difference, Heat of Mixing and Period of Constituent Elements and Its Application to Characterization of the Main Alloying Element, Mater. Trans., 2005, 46(12), p 28172829

37. M. Mihalkovic, M. Widom, Alloy Database. http://alloy.phys. cmu.edu/. Accessed 22 May 2017

38. S. Curtarolo, W. Setyawan, S. Wang, J. Xue, K. Yang, R.H. Taylor, L.J. Nelson, G.L.W. Hart, S. Sanvito, M. BuongiornoNardelli, N. Mingo, and O. Levy, AFLOWLIB.ORG: A Distributed Materials Properties Repository from High-Throughput Ab Initio Calculations, Comput. Mater. Sci., 2012, 58, p 227-235

39. C. Wolverton, Open Quantum Materials Database. http://oqmd. org/. Accessed 22 May 2017

40. J. Saal, S. Kirklin, M. Aykol, B. Meredig, and C. Wolverton, Materials Design and Discovery with High-Throughput Density Functional Theory: The Open Quantum Materials Database (OQMD), JOM, 2013, 65(11), p 1501-1509, in English

41. S. Kirklin, J.E. Saal, B. Meredig, A. Thompson, J.W. Doak, M. Aykol, S. Rühl, and C. Wolverton, The Open Quantum Materials Database (OQMD): Assessing the Accuracy of DFT Formation Energies, Npj Comput. Mater., 2015, 1, p 15010

42. A. Jain, S.P. Ong, G. Hautier, W. Chen, W.D. Richards, S. Dacek, S. Cholia, D. Gunter, D. Skinner, G. Ceder, and K.A. Persson, Commentary: The Materials Project: A Materials Genome Approach to Accelerating Materials Innovation, APL Mater., 2013, 1(1), p 011002

43. W. Cao, S.L. Chen, F. Zhang, K. Wu, Y. Yang, Y.A. Chang, R. Schmid-Fetzer, and W.A. Oates, PANDAT Software with PanEngine, PanOptimizer and PanPrecipitation for Multi-component Phase Diagram Calculation and Materials Property Simulation, Calphad, 2009, 33(2), p 328-342

44. R. Schmid-Fetzer, Progress in Thermodynamic Database Development for ICME of Mg Alloys, Magnesium Technology 2015, M.V. Manuel, A. Singh, M. Alderman, and N.R. Neelameggham, Ed., Wiley, London, 2015, p 283-287

45. J.O. Andersson, T. Helander, L. Hoglund, P. Shi, and B. Sundman, Thermo-Calc \& DICTRA, Computational Tools for Materials Science, Calphad, 2002, 26(2), p 273-312
46. M. Winter, The University of Sheffield and WebElements Ltd, UK. www.webelements.com. Accessed 22 May 2017

47. C. Kittel, Introduction to Solid State Physics, 8th ed., John Wiley \& Sons Inc, New York, 2005

48. A.T. Dinsdale, SGTE Data for Pure Elements, Calphad, 1991, 15(4), p 317-425

49. A.L. Allred, Electronegativity Values from Thermochemical Data, J. Inorg. Nucl. Chem., 1961, 17(3-4), p 215-221

50. D.J.M. King, A.G. McGregor, Alloy Search and Predict. www. alloyASAP.com. Accessed 22 May 2017

51. R. Li, J.C. Gao, and K. Fan, Microstructure and Mechanical Properties of $\mathrm{MgMnAlZnCu}$ High Entropy Alloy Cooling in Three Conditions, Mater. Sci. Forum, 2011, 686, p 235-241

52. K.M. Youssef, A.J. Zaddach, C. Niu, D.L. Irving, and C.C. Koch, A Novel Low-Density, High-Hardness, High-Entropy Alloy with Close-packed Single-Phase Nanocrystalline Structures, Mater. Res. Lett., 2015, 3(2), p 95-99

53. E. Doernberg, A. Kozlov, and R. Schmid-Fetzer, Experimental Investigation and Thermodynamic Calculation of $\mathrm{Mg}$-Al-Sn Phase Equilibria and Solidification Microstructures, J. Phase Equilib. Diffus., 2007, 28(6), p 523-535

54. B.P. Alblas, W. van der Lugt, J. Dijkstra, and C. van Dijk, Structure of Liquid Li-Sn Alloys, J. Phys. F Met. Phys., 1984, 14(9), p 1995-2006

55. D. Li, S. Fürtauer, H. Flandorfer, and D.M. Cupid, Thermodynamic Assessment and Experimental Investigation of the $\mathrm{Li}-\mathrm{Sn}$ System, Calphad, 2014, 47, p 181-195

56. O.N. Senkov and D.B. Miracle, Effect of the Atomic Size Distribution on Glass Forming Ability of Amorphous Metallic Alloys, Mater. Res. Bull., 2001, 36(12), p 2183-2198

57. F.E. Wang, Bonding Theory for Metals and Alloys, Elsevier, Amsterdam, 2005

58. S. Fang, X. Xiao, L. Xia, W. Li, and Y. Dong, Relationship Between the Widths of Supercooled Liquid Regions and Bond Parameters of Mg-Based Bulk Metallic Glasses, J. Non-Cryst. Solids, 2003, 321(1-2), p 120-125

59. C. Kittel, Introduction to Solid State Physics, 6th ed., John Wiley \& Sons Inc, London, 1980

60. XRD, International Tables for X-Ray Crystallography, Birmingham, England, 1968

61. J.L.C. Daams, P. Villars, and J.H.N. van Vucht, Atlas of Crystal Structure Types for Intermetallic Phases, ASM International, Materials Park, 1991 